\title{
SYSTEM RELIABILITY ASSESSMENT OF 3D STEEL FRAMES DESIGNED PER AISC LRFD SPECIFICATIONS
}

\author{
S. Zhang ${ }^{1}$ and W. Zhou ${ }^{2, *}$ \\ ${ }^{1}$ PhD candidate, Civil and Environmental Engineering, Western University, London, Ontario, Canada N6A 5B9 \\ ${ }^{2}$ Assistant Professor, Civil and Environmental Engineering, \\ Western University, London, Ontario, Canada N6A 5B9 \\ *(Corresponding author: E-mail: wzhou@eng.uwo.ca)
}

Received: 5 October 2012; Revised: 23 October 2012; Accepted: 20 November 2012

\begin{abstract}
This paper presents the system reliability analysis of a three-dimensional steel frame designed per AISC LRFD with respect to the collapse limit state under the dead and live loads. The system reliability is evaluated using the first-order reliability method (FORM)-based adaptive response surface approach. The uncertainties in the material properties, geometric properties of frame members, initial geometric imperfection of the structure, dead load and live load as well as the spatial variability of the live load are accounted for in the reliability analysis. The analysis results suggest that the system reliability of the example frame is similar to that of the planar steel frames designed per AISC LRFD and evaluated in a previous study. It is observed that the spatial variability of the live load leads to a decreased system reliability. Results of the sensitivity analysis indicate that the failure probability of the example frame increases by almost one order of magnitude if the coefficient of variation of the steel yield strength increases from 0.06 to 0.1 . Furthermore, the system reliability decreases drastically if the upper bound of the magnitude of initial geometric imperfection is greater than $0.4 \%$ of the overall height of the example frame.
\end{abstract}

Keywords: Three-dimensional steel frame, System reliability, Response surface approach, FORM, Advanced analysis

\section{INTRODUCTION}

The limit states design or load and resistance factors design (LRFD) codes for building structures, e.g. AISC LRFD [1-2] and CSA S16-09 [3], are generally developed by considering the reliability of individual members in a structure. However, failure of an individual member in a structure does not necessarily lead to the failure of the entire structural system due to the structure redundancy or the force redistribution after the member failure. Therefore, the reliability of a structural system is typically higher than that of individual members in the structure (Ellingwood [4-5]; Zhou and Hong [6]). With the advances in numerical computation and increased acceptance of the performance-based design, knowledge about the reliability levels of structural systems becomes more accessible as well as important for both researchers and practitioners (Ellingwood [5]; Li and Li [7]).

The system reliability of steel frame structures has been investigated in the past (e.g. Zhou and Hong [6]; Buonopane et al. [8-9]). Zhou and Hong [6] evaluated the member and system reliability of four planar steel frames designed per AISC LRFD [1] by considering the uncertainties in the dead load, live load and steel yield strength. The member reliability was evaluated based on the load effects obtained from a first-order elastic analysis and equations that indirectly take into account the second-order effects; whereas the system reliability of the structure was evaluated based on the collapse load factor-based limit state function, in which the collapse load factor was calculated by using the refined second-order elastic-plastic hinge method (Chen et al. [10]). The Monte Carlo techniques and first-order reliability method (FORM) were employed to evaluate the member and system reliability. They reported that the probabilities of collapse of the steel frames considered are approximately one order of magnitude lower than the failure probabilities of the most critical members in the frames. 
Buonopane et al. [8] evaluated the reliability of two-story two-bay planar steel frames designed according to two design methods, namely the AISC LRFD [2] and the so-called advanced analysis approach that evaluates the load capacity (i.e. collapse load) of the entire structural system by directly accounting for the second-order effects (both $P-\Delta$ and $P-\delta$ effects), plastic hinging, residual stress and geometric imperfection in the analysis. The uncertainties in the load (both dead load and live load) and steel yield strength were considered in the reliability analysis. The reliability was evaluated with respect to the limit states associated with collapse as well as occurrence of the first plastic hinge in the structure. The analysis results revealed that the structures designed per AISC LRFD generally have higher system reliability than those designed using the advanced analysis approach.

Buonopane et al. [9] investigated the probabilistic characteristics of the collapse load and system reliability of two planar steel frames that were designed using the first-order elastic analysis, modified by the effective length factors and magnification factors to approximately account for the second-order effects. The uncertainties in the yield strength, Young's modulus, geometric imperfection and peak compressive residual stress were taken into account in their investigation. The system reliability of planar steel portal frames with tapered beams and columns has been reported in the literature ( $\mathrm{Li}$ and $\mathrm{Li}$ [7]), where a second-order plastic analysis was used to evaluate the collapse load of the structure. Huh et al. [11] studied the reliability of planar steel frames with or without shear walls using the nonlinear finite element method and FORM. Hadianfard and Razani [12] evaluated the reliability of semi-rigid planar steel frames. Note that the above-mentioned previous studies on the system reliability of steel frames are all focused on two-dimensional frames.

Recently, system reliability assessments of three-dimensional (3D) steel scaffold systems were reported in the literature (Zhang et al. [13-15]). In these investigations, the ultimate load capacity of the scaffold system was predicted using the advanced analysis approach by taking into account the material and geometry nonlinearity, initial geometric imperfections, joint details, and residual stresses. The model uncertainty was characterized by comparing the experimentally determined ultimate load capacities with those predicted using the advanced analysis approach for fifteen full-scale scaffold specimens (Zhang et al. [14]). The probabilistic characteristics of the ultimate load capacity were obtained from Monte Carlo simulation considering the model uncertainty as well as the uncertainties associated with material properties, initial geometric imperfections, load eccentricity and joint stiffness. Given the statistics of the resistance and applied loads, the system reliability was estimated using the FORM. Note that the steel scaffold systems are relatively simple 3D structures compared with 3D building structures. To the best knowledge of the authors of this paper, system reliability analysis of 3D steel building frames has not been reported in the literature.

The objective of the study reported in this paper was to carry out system reliability analyses of 3D steel frame structures. To this end, a realistic 3D steel frame example designed per AISC LRFD [1] was considered. The reliability was evaluated with respect to the collapse limit state, with the collapse load of the structure evaluated using the advanced analysis implemented in the finite element software SAP2000 [16]. The analysis methodologies and results are described in the following sections. 


\section{METHODOLOGY FOR SYSTEM RELIABILITY EVALUATION}

\subsection{Limit State Function}

Without loss of generality, consider a structure subjected to the gravity loads only. Let $R(\boldsymbol{X})$ and $S(\boldsymbol{Y})$ denote the random variables representing the collapse load (i.e. resistance) of the structure and total external loads applied on the structure, respectively. The notation $R(\boldsymbol{X})$ was used to emphasize that the resistance, $R$, is a function of a set of random variables, $\boldsymbol{X}$, such as the material properties (e.g. yield strength and Young's modulus) of steel, cross-sectional properties (e.g. cross-sectional area and moment of inertia) of individual members in the structure, initial geometric imperfections and model uncertainty, whereas $S(\boldsymbol{Y})$ is a function of a vector of random variables, $\boldsymbol{Y}$, such as the dead load, live load, as well as geometric properties of the structure. Let $r(\boldsymbol{x})$ and $s(\boldsymbol{y})$ denote the realizations of $R(\boldsymbol{X})$ and $S(\boldsymbol{Y})$, respectively. The limit state function corresponding to the collapse of the structure can be written as

$g(r(\boldsymbol{x}), s(\boldsymbol{y}))=r(\boldsymbol{x})-s(\boldsymbol{y})$

Therefore, $g \leq 0$ indicates that the structure with a resistance of $r(x)$ will collapse under the external loads $s(y)$, whereas $g>0$ indicates that the structure is safe.

The total external loads $s(y)$ can be easily calculated given the load condition and geometric properties of the structure. In most cases, analytical solutions are however not available to evaluate the resistance $r(\boldsymbol{x})$; therefore, numerical approaches such as the finite element method are needed to evaluate $r(\boldsymbol{x})$.

\subsection{Evaluation of the Collapse Load}

The advanced analysis as implemented in SAP2000 was used to evaluate the collapse load of the $3 \mathrm{D}$ steel frame in this investigation. The main assumptions involved in the advanced analysis approach in SAP2000 are: 1) the material (steel) is elastic-perfectly plastic; 2) geometric nonlinearities including the $P-\Delta$ and large displacement effect are considered; 3 ) all joints are rigid and each floor is characterized as a rigid diaphragm; 4) all beams are subjected to zero axial force and unidirectional bending about either the strong or weak axis, and all columns are subjected to non-zero axial forces and bi-directional bending about both the strong and weak axes; 4) no composite action between the steel beam and concrete floor; 5) all beams and columns have compact cross sections, i.e. local buckling not considered; 6) no lateral-torsional buckling failure for beams or columns; 7) the capacity of a beam-column is represented by the axial force-bending moment interaction equations specified in AISC LRFD 2005 with the resistance factors set to unity; 8 ) once a plastic hinge has formed, the cross-sectional forces at the plastic hinge move on the axial and moment interaction surface as the load further increases, and 9) the external load is applied proportionally and incrementally.

The interaction equation for a beam-column subjected to axial force and bi-directional bending moments is given by (AISC [2])

$$
\begin{aligned}
& \frac{P}{P_{r}}+\frac{8}{9}\left(\frac{M_{x}}{M_{p x}}+\frac{M_{y}}{M_{p y}}\right) \leq 1.0 \quad \frac{P}{P_{r}} \geq 0.2 \\
& \frac{P}{2 P_{r}}+\left(\frac{M_{x}}{M_{p x}}+\frac{M_{y}}{M_{p y}}\right) \leq 1.0, \frac{P}{P_{r}}<0.2
\end{aligned}
$$


where $P$ is the applied axial force; $P_{r}$ is the axial tensile or compressive strengths; $M_{x}$ and $M_{y}$ are the applied bending moments with respect to the strong $(x)$ axis and weak $(y)$ axis, respectively, and $M_{p x}$ and $M_{p y}$ are the flexural strengths with respect to the strong and weak axes.

The flexural strengths can be calculated as $M_{p x}=f_{y} Z_{x}$ and $M_{p y}=f_{y} Z_{y}$, respectively, where $Z_{x}$ and $Z_{y}$ correspond to the plastic section moduli about the $x$-axis and $y$-axis, and $f_{y}$ is the steel yield strength. The axial tensile strength of a beam-column is calculated assuming gross section yielding, i.e. $P_{r}=$ $f_{y} A_{g}$, where $A_{g}$ is the gross cross-sectional area. The axial compressive strength of the member is given by

$$
P_{r}=\left\{\begin{array}{cc}
f_{y} A_{g}\left(0.658^{\frac{f_{y}}{F_{e}}}\right) & F_{e} \geq 0.44 f_{y} \\
0.877 F_{e} A_{g} & F_{e}<0.44 f_{y}
\end{array}\right.
$$

where $F_{e}$ is the elastic critical buckling stress determined by $F_{e}=\pi^{2} E /(K L / r)^{2}$, where $K$ is the effective length factor of the column; $L$ is the column length; $r$ is the radius of gyration about the axis of buckling, and $E$ is Young's modulus for steel.

The advanced analysis allows the development of the relationship between the applied load and displacement at a given point on the structure (e.g. the horizontal displacement at the top of the structure). The collapse load of the structure is then obtained as the total load corresponding to the peak point on the load-displacement curve. Because initial geometric imperfection of columns (an out-of-straightness of the span length over 1,500 at midspan) and residual stresses have been implicitly accounted for in the AISC interaction equation given by Eq. 2 (Chen et al. [10]), their impact on the collapse load is implicitly taken into account in the analysis.

\subsection{System Reliability Evaluation}

The system failure probability of a 3D steel frame can be expressed as the following multidimensional integral over the failure domain $\mathrm{g}(r(\boldsymbol{x}), s(\boldsymbol{y})) \leq 0$ :

$P_{f}=\operatorname{Pr}(g(r(\boldsymbol{x}), s(\boldsymbol{y})) \leq 0)=\int_{g(r(\boldsymbol{x}), s(\boldsymbol{y})) \leq 0} f_{Z}(\boldsymbol{z}) d \boldsymbol{z}$

where $\boldsymbol{Z}=\boldsymbol{X} \cup \boldsymbol{Y}$ (" $\cup$ " indicates the union operation) is a vector of basic random variables on which the structural resistance and total load are dependent, and $f_{\boldsymbol{Z}}(\boldsymbol{z})$ is the joint probability density function of $\boldsymbol{Z}$.

It is usually not feasible to obtain an analytical solution of the failure probability defined by Eq. 4 . The Monte Carlo simulation is an accurate and robust technique to evaluate this integration; however, this method is time-consuming for the cases that have low failure probabilities. Approximate approaches such as the first- and second-order reliability methods (FORM and SORM) (Rackwitz and Fissler [17]; Low and Tang [18]; Breitung [19]; Der Kiureghian [20]) can be used to evaluate the integral in Eq. 4. However, incorporating the finite element method required to evaluate the collapse load into the FORM/SORM may give rise to numerical difficulties in the reliability analysis, as reported by Zhou and Hong [6]. 
A reasonable trade-off between efficiency, accuracy and robustness in the reliability analysis can be achieved through the response surface approach. The application of response surface approach in the system reliability evaluation has been reported in the literature. For example, this method was used by Huh and Haldar [21] to calculate non-linear seismic reliability of planar frames. Zhao and Ono [22] also used the response surface approach to investigate the system reliability of planar framed structures using the collapse load factor-based limit state function.

In this study, a so-called FORM-based adaptive response surface approach was used to evaluate the system reliability of 3D steel frames. The method involves constructing a sequence of response surfaces to approximate the collapse load (i.e. resistance) of 3D steel frames. For each response surface, the collapse load, $R$, is approximated by a second-order polynomial (Bucher and Bourgund [23]) as follows:

$$
R(\boldsymbol{X}) \approx a_{0}+\sum_{i=1}^{n} b_{i} X_{i}+\sum_{i=1}^{n} c_{i} X_{i}^{2}
$$

where $\boldsymbol{X}=\left(X_{1}, X_{2}, \ldots, X_{n}\right)$ denotes the vector of random variables on which the resistance is dependent; the mean and standard deviation of $X_{i}(i=1,2, \ldots, n)$ are denoted by $m_{i}$ and $\sigma_{i} ; a_{0}, b_{i}$ and $c_{i}$, are the $2 n+1$ unknown coefficients to be determined, and $n$ is the total number of random variables. In order to determine the $2 n+1$ coefficients in Eq. 5, the collapse load needs to be determined using the advanced analysis corresponding to at least $2 n+1$ sets of sampling points. These sampling points are adaptively selected as described in the following calculation steps.

1) Evaluate the resistance $R(\boldsymbol{X})$ at the mean value point $\left(m_{1}, m_{2}, \ldots, m_{i}, \ldots, m_{n}\right)$ and the $2 n$ points each at $\left(m_{1}, m_{2}, \ldots, m_{i} \pm h \sigma_{i}, \ldots, m_{n}\right)$ through the advanced analysis; the value of $h$ was selected to equal 3 (Bucher and Bourgund [23]);

2) Use the $2 n+1$ sets of sampling points and corresponding values of $R(\boldsymbol{X})$ from Step 1) to solve Eq. 5 for the coefficients $a_{0}, b_{i}$ and $c_{i}$, which leads to a tentative response surface for the resistance;

3) Carry out the FORM to obtain the reliability index based on the tentative response surface obtained in Step 2) and the corresponding design point $\boldsymbol{x}^{*}$;

4) Construct a new tentative response surface for the resistance based on sampling points corresponding to the tentative design point $\boldsymbol{x}^{*}$ and the $2 n$ points each at $\left(x_{1}{ }^{*}, x_{2}{ }^{*}, \ldots, x_{i}{ }^{*} \pm h \sigma_{i}, \ldots, x_{n}{ }^{*}\right)$ $(i=1,2, \ldots, n)$; carry out the FORM to obtain a new reliability index and an updated tentative design point;

5) Repeat Step 4) until the calculated reliability index has converged, i.e. the absolute difference between the reliability indices corresponding to two consecutive tentative response surfaces being less than a pre-defined tolerance. The failure probability, $P_{f}$, can then be approximated by

$P_{f} \approx \Phi(-\beta)$

where $\Phi(\bullet)$ denotes the standard normal cumulative distribution function and $\beta$ is the converged reliability index obtained from the FORM-based adaptive response surface approach. 


\section{NUMERICAL EXAMPLE}

\subsection{Example Description}

In this study, the system reliability of a 3D unbraced steel framed structure (see Figure 1) designed by Ziemian [24]; Ziemian et al. [25] per ASCI LRFD [1] was evaluated using the methodology described in Section 2. The plan of the frame is shown in Figure 2, and the two elevations of the frame are shown in Figures 3(a) and (b), respectively. The dashed lines in Figure 2 represent simply supported beams (ignored in the numerical analysis) on typical floors. Therefore, the distribution of the gravity loading is approximated by uniformly distributed loads on interior girders spanning in the N-S direction and as concentrated loads at the mid-spans of the E-W girders. The frame consists of three similar bents spanning in the E-W direction and nine bents spanning in the N-S direction. The bents in the N-S direction are either six column exterior bents or three column interior bents as shown in Figure 2. All beam webs are in the vertical plane and all column webs are in the N-S plane. Furthermore, in the finite element model for the advance analysis, all columns are fully fixed at the base and their effective length factors were automatically calculated by SAP2000. To expedite the analysis, each beam or column was represented by one beam element, and plastic hinges were assumed to only take place at the two ends of the member.

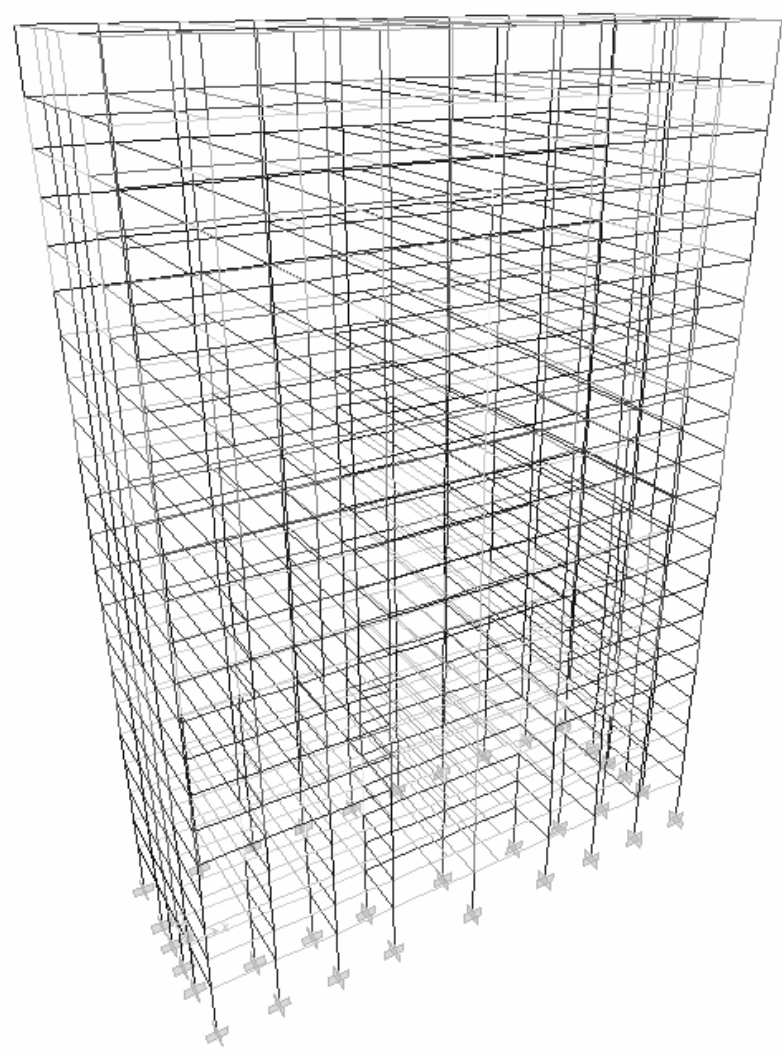

Figure 1.3D Model of the Example Frame 


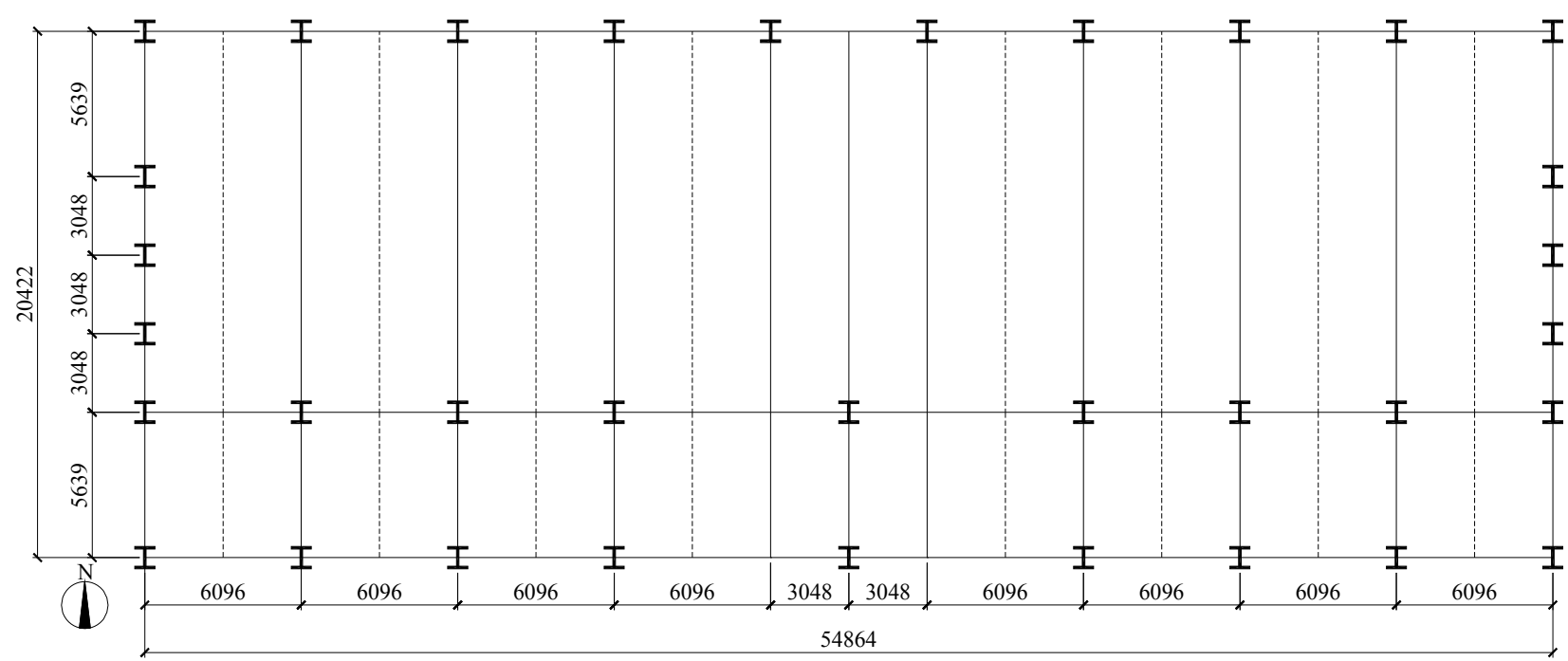

Figure 2. Plan of the Example Frame (Unit: mm)

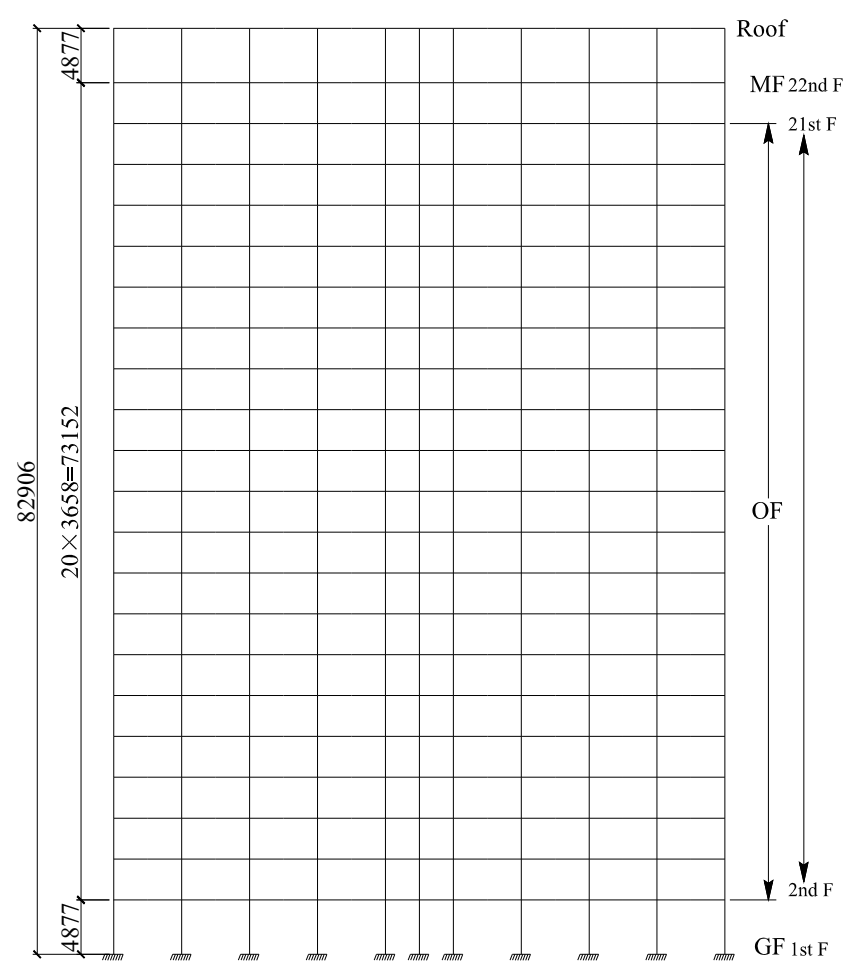

(a)

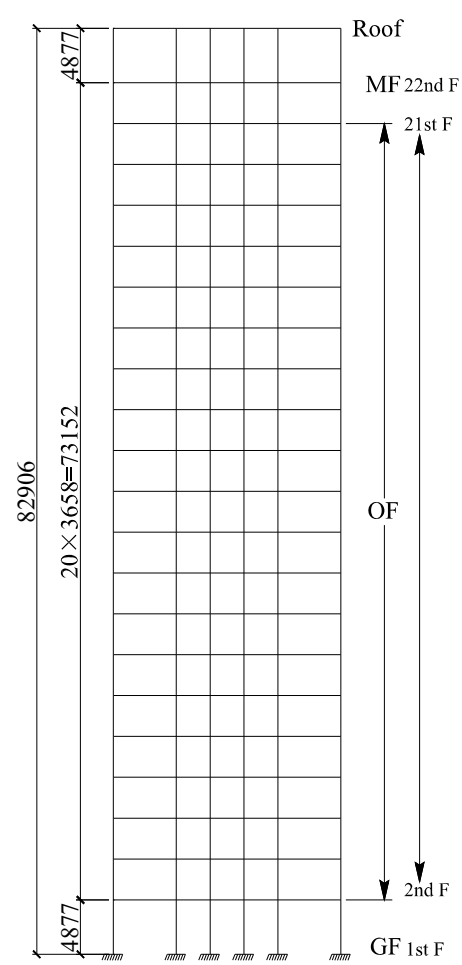

(b)

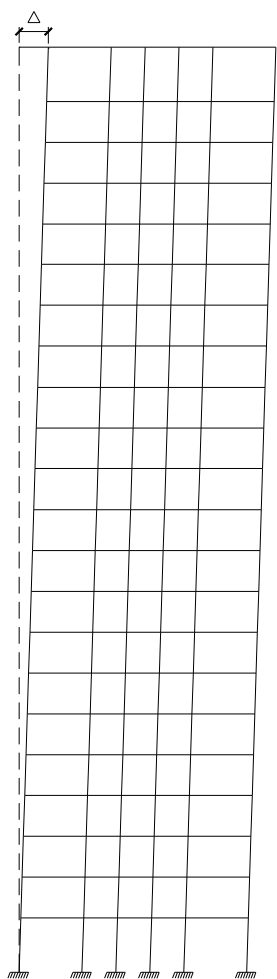

(c)

Figure 3. (a) N-S Elevation (b) W-E Elevation (c) Initial Geometric Imperfection Distribution (Unit: $\mathrm{mm}$ )

GF: Ground Floor OF: Office Floor MF: Mechanical Floor

The building has an overall height $(H)$ of $82.906 \mathrm{~m}$ ( 272 feet) and consists of 22 stories, including 20 office levels (from the $2^{\text {nd }}$ floor to the $21^{\text {st }}$ floor) with the same floor-height of $3.658 \mathrm{~m}$ (12 feet), one mechanical level occupying the $22^{\text {nd }}$ floor and one ground floor (see Figures 3(a) and 3(b)). Both the mechanical and ground floors are $4.877 \mathrm{~m}$ (16 feet) high. All members are designed using A36 steel with a specified yield strength of $248 \mathrm{MPa}$ and a nominal Young's modulus of 200,000 MPa (Ziemian [24]). Only the dead and live loads were included in the reliability analysis because Ziemian [24] indicated that the combination of the factored dead load (D) and live load (L) $(1.2 \mathrm{D}+1.6 \mathrm{~L})$ governs the LRFD design of this structure. The nominal dead load on all the floors equals $3.6 \mathrm{kN} / \mathrm{m}^{2}$. In addition, the nominal dead load of the building facade equals 2.2 $\mathrm{kN} / \mathrm{m}^{2}$ (distributed over the four vertical surfaces of the building). Three different nominal live 
loads are assumed for the building, namely $2.4 \mathrm{kN} / \mathrm{m}^{2}$ on the office floor (i.e. $2^{\text {nd }}$ to $21^{\text {st }}$ floors), 12 $\mathrm{kN} / \mathrm{m}^{2}$ on the mechanical floor (i.e. $22^{\text {nd }}$ floor), and $1.2 \mathrm{kN} / \mathrm{m}^{2}$ on the roof.

\subsection{Statistic Properties of Random Variables}

The random variables considered in the reliability analysis included the steel yield strength, Young's modulus, cross-sectional area and moment of inertia of individual members, initial geometric imperfection, dead and live loads. Due to a lack of information, the model uncertainty associated with the collapse load was ignored. To simplify the analysis, the yield strength, Young's modulus, cross-sectional area and moment of inertia of different members were assumed to be fully correlated. The ratios between the cross-sectional areas (or moments of inertia) of different members were assumed to be the same as those between the corresponding nominal properties. The same dead load was assumed to apply on all the floors; that is, the dead loads on all the floors are identical and fully correlated. Furthermore, the floor dead load and facade dead load were assumed to be fully correlated, with the ratio between the two loads equal to that between the corresponding nominal loads.

Table 1. Statistic Parameters of Random Variables

\begin{tabular}{|c|c|c|c|c|c|c|}
\hline Property & Random variables & Nominal value & Mean/Nominal & $\mathrm{COV}$ & $\begin{array}{l}\text { Probability } \\
\text { Distribution }\end{array}$ & Source \\
\hline \multirow{2}{*}{$\begin{array}{c}\text { Material } \\
\text { property } \\
(\mathrm{MPa})\end{array}$} & Yield strength & 248 & 1.1 & 0.06 & Normal & \multirow{2}{*}{$\begin{array}{l}\text { Bartlett et al. } \\
\quad[26]\end{array}$} \\
\hline & Young's modulus & 200,000 & 0.993 & 0.034 & Normal & \\
\hline \multirow{2}{*}{$\begin{array}{c}\text { Geometric } \\
\text { property }\end{array}$} & Cross-sectional area & varies & 1.0 & 0.05 & Lognormal & \multirow{2}{*}{$\begin{array}{c}\text { Huh et al. } \\
\text { [11] }\end{array}$} \\
\hline & Moment of inertia & varies & 1.0 & 0.05 & Lognormal & \\
\hline $\begin{array}{c}\text { Initial } \\
\text { geometric } \\
\text { imperfection }\end{array}$ & $\begin{array}{l}\text { Maximum lateral } \\
\text { sway }(\Delta) \text { at the top }\end{array}$ & N/A & $H / 1,000^{\mathrm{a}}$ & 0.577 & Uniform & $\begin{array}{c}\text { Buonopane et al. } \\
\text { [9] }\end{array}$ \\
\hline \multirow{2}{*}{ Load $\left(k N / m^{2}\right)$} & Dead load & $3.6(2.2)^{\mathrm{b}}$ & 1.05 & 0.1 & Normal & \multirow{2}{*}{$\begin{array}{c}\text { Ellingwood et al. } \\
\text { [27] }\end{array}$} \\
\hline & Live load & $2.4(12,1.2)^{\mathrm{c}}$ & 1.0 & 0.25 & Gumbel & \\
\hline \multirow{2}{*}{ Live load ratio $^{\mathrm{d}}$} & $K_{1}$ & 5 & 1.057 & 0.346 & Gumbel & \multirow{2}{*}{ Fitted distribution } \\
\hline & $K_{2}$ & 0.5 & 1.062 & 0.345 & Gumbel & \\
\hline
\end{tabular}

${ }^{\mathrm{a}} \mathrm{H} / 1,000$ is the mean value of the maximum lateral sway at the top of structure.

b $3.6 \mathrm{kN} / \mathrm{m}^{2}$ is the interior load of the building and $2.2 \mathrm{kN} / \mathrm{m}^{2}$ is the exterior façade load of the building.

${ }^{c} 2.4 \mathrm{kN} / \mathrm{m}^{2}, 12 \mathrm{kN} / \mathrm{m}^{2}$ and $1.2 \mathrm{kN} / \mathrm{m}^{2}$ are the nominal uniformly distributed live loads on the office floors, mechanical floor and roof, respectively.

d The nominal values of $K_{1}$ and $\mathrm{K}_{2}$ were calculated based on the nominal uniform live loads on office floors, mechanical floor and roof; their probabilistic characteristics (mean and standard deviation) were calculated using simulation and distribution type was determined through fitting methodology.

Two cases were considered regarding the correlation between the live loads on different floors. The first case assumes that the live loads on all the floors are fully correlated; that is, the same live load is applied on all the office floors (i.e. $2^{\text {nd }}$ to $21^{\text {st }}$ floors), whereas the ratio between the live loads on the office floor and mechanical floor (or roof) equals that between the corresponding nominal live loads. The second case assumes that the same live load is applied on all the office floors and that the live loads on the roof, mechanical floor and office floor are independent of each other. Let $K_{1}$ denote the ratio of the live load on the mechanical floor to that on the office floor, and let $K_{2}$ denote the ratio of the live load on the roof to that on the office floor. It follows that $K_{1}$ and $K_{2}$ are independent random variables in the second case. Furthermore, the resistance of the 
steel frame depends on $K_{1}$ and $K_{2}$, i.e. the relative magnitudes between the live loads on different floors. Therefore, the response surface for the resistance is a function of $K_{1}$ and $K_{2}$, in addition to the material and geometric properties in the second case. The Monte Carlo simulation was carried out to derive the probabilistic characteristics of $K_{1}$ and $K_{2}$ based on the probabilistic characteristics of the live loads on the roof, mechanical floor and office floor.

The initial geometric imperfection of the frame was assumed to be in the form of lateral sway linearly distributed along the height of the structure with zero sway at the base and the maximum sway $(\Delta)$ at the top (see Figure 3(c)) (Buonopane et al. [9]). It is further assumed that the initial imperfection exists in the N-S direction only. The probabilistic characteristics of the random variables considered in this study are summarized in Table 1. All the random variables were assumed to be independent of each other in the analysis.

\subsection{Analysis Results}

The reliability indices calculated from the FORM and the corresponding sensitivity factors associated with the random variables involved in the analysis are summarized in Table 2 . The table shows that the reliability index, $\beta_{1}$, for Case 1 (i.e. the live loads on all the floors are fully correlated) equals 3.59 and that the reliability index, $\beta_{2}$, for Case 2 (i.e. the live loads on the roof, mechanical floor and office floor are independent of each other) equals 3.54. These reliability index values are similar to those of the planar steel frames designed per AISC LRFD [1] and evaluated by Zhou and Hong [6]. Note that $\beta_{1}$ is slightly higher than $\beta_{2}$. This suggests that the spatial variability of the live load reduces the system reliability of the example frame. The impact of the spatial variability is however small for this example, because the live loads on the majority of the floors (i.e. office floors) were assumed to be fully correlated in Case 2.

The sensitivity factors for the moment of inertia and cross-sectional areas shown in Table 2 are almost zero, which suggests that the system reliability is insensitive to the inaccuracies in these two parameters. The sensitivity factors associated with the material properties indicate that the impact of the yield strength on the system reliability is, as expected, much higher than that of Young's modulus. Furthermore, the system reliability is somewhat sensitive to the inaccuracy in the magnitude of initial geometric imperfection. The live load has the most significant impact on the system reliability in that it is associated with the highest sensitivity factor, which equals approximately 0.75 for both Cases 1 and 2. Finally, the results for Case 2 indicate that the system reliability index is sensitive to $K_{1}$, i.e. the ratio between the live load on the mechanical floor and that on the office floor.

Sensitivity analyses were carried out to investigate the impact of the variability of the yield strength and magnitude of the initial geometric imperfection on the system reliability of the 3D frame example. The live loads on all the floors were assumed to be fully correlated in the sensitivity analysis. To expedite the analysis, the response surface for the resistance, $R$, was not adaptively constructed in the sensitivity analysis, but instead approximated by the response surface corresponding to the converged reliability index (i.e. $\beta_{1}$ ) obtained for Case 1 shown in Table 2. The sensitivity analysis results are shown in Figures 4 and 5. 
Table 2 Reliability Index, Failure Probability and the Sensitivity Factors

\begin{tabular}{|c|c|c|c|}
\hline \multicolumn{2}{|c|}{ Results } & Case 1 & Case 2 \\
\hline \multicolumn{2}{|c|}{ Reliability index } & 3.59 & 3.54 \\
\hline \multicolumn{2}{|c|}{ Failure probability } & $1.65 \times 10^{-4}$ & $2 \times 10^{-4}$ \\
\hline \multirow{9}{*}{$\begin{array}{l}\text { Sensitivity } \\
\text { factor }\end{array}$} & Yield strength & -0.5277 & -0.4608 \\
\hline & Young's modulus & -0.0251 & 0.0378 \\
\hline & Cross-sectional area & -0.00028 & 0.00025 \\
\hline & Inertial moment & $-1.18 \times 10^{-6}$ & $6.97 \times 10^{-6}$ \\
\hline & $\begin{array}{l}\text { Initial geometric } \\
\text { imperfection }\end{array}$ & 0.0955 & 0.0633 \\
\hline & Dead load & 0.3687 & 0.3462 \\
\hline & Live load & 0.7588 & 0.7438 \\
\hline & $K_{1}$ & - & 0.3244 \\
\hline & $K_{2}$ & - & -0.0620 \\
\hline
\end{tabular}

Figure 4 depicts the system reliability indices and corresponding failure probabilities versus the coefficients of variation (COV) of the yield strength with values ranging from 0.01 to 0.1 . The figure shows that the system reliability decreases as the COV of the yield strength increases. For example, the reliability index equals 3.59 and 2.97 corresponding to the COV values of 0.06 and 0.1 respectively. In other words, the system failure probability increases by almost one order of magnitude as the COV of the yield strength increases from 0.06 to 0.1 . This suggests that good quality control in the steel manufacturing process has a significant contribution to the system reliability of steel frames.

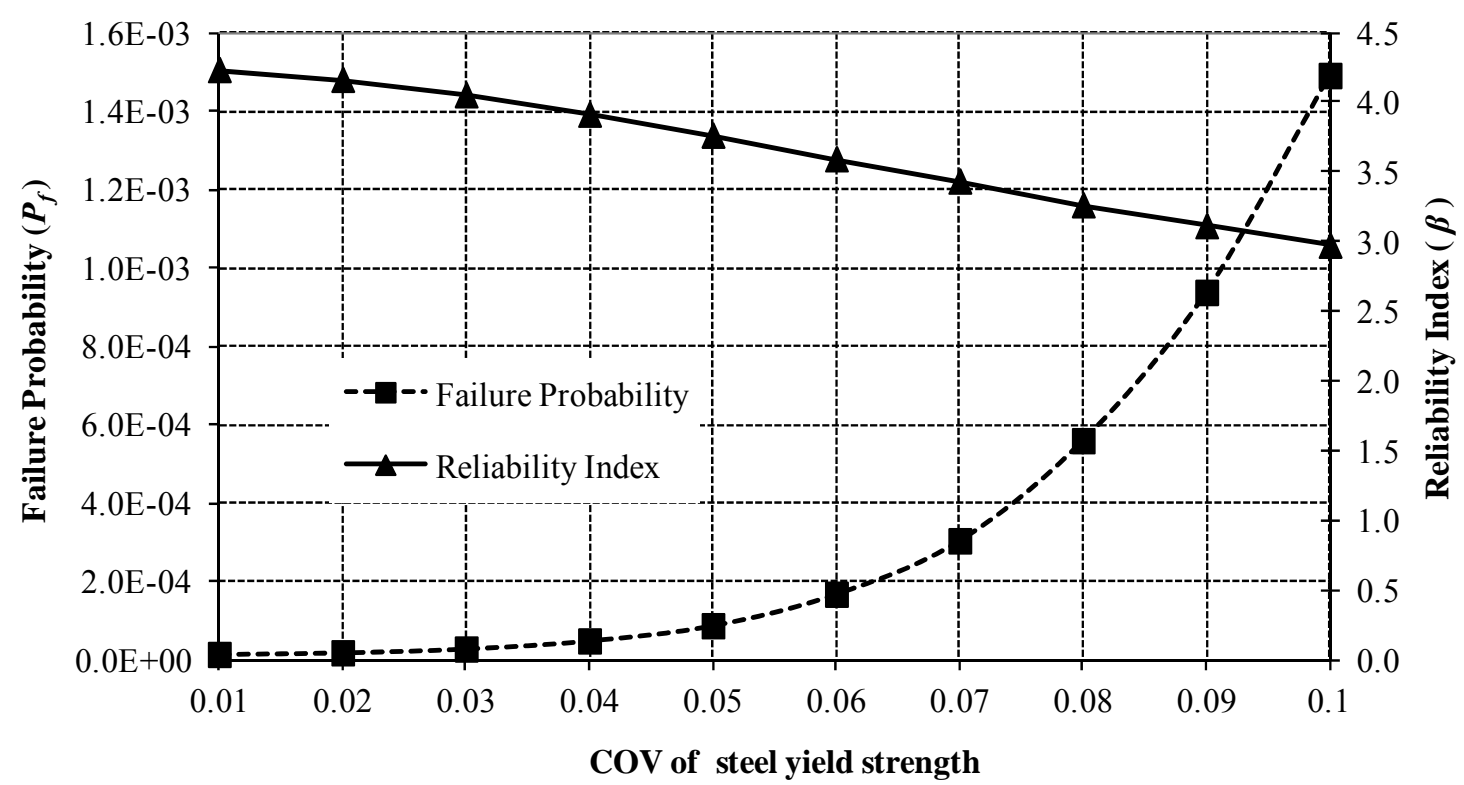

Figure 4. System Reliability Versus COV of Steel Yield Strength

Figure 5 depicts the system reliability as a function of the magnitude of the initial geometric 
imperfection characterized by the upper bound value of the maximum lateral sway that is assumed to be uniformly distributed with a lower bound of zero. The results indicate that the system reliability is relatively insensitive to the upper bound value of the maximum lateral sway as long as it is less than or equal to $H / 300$. For example, the system reliability index equals 3.62 corresponding to an upper bound of the maximum lateral sway of $H / 600$, and decreases to 3.40 if the upper bound increases to $H / 300$. However, the system reliability decreases drastically if the upper bound of the maximum lateral sway is greater than $H / 250$ : the reliability index declines from 3.22 to 2.02 if the upper bound of the maximum lateral sway increases from $H / 250$ to $H / 150$. It can be inferred that the system reliability for the example structure is markedly reduced if the upper bound of the maximum lateral sway is greater than twice the maximum allowable erection tolerance $(H / 500)$ specified by AISC [2] assuming that the maximum lateral sway is uniformly distributed with a lower bound of zero.

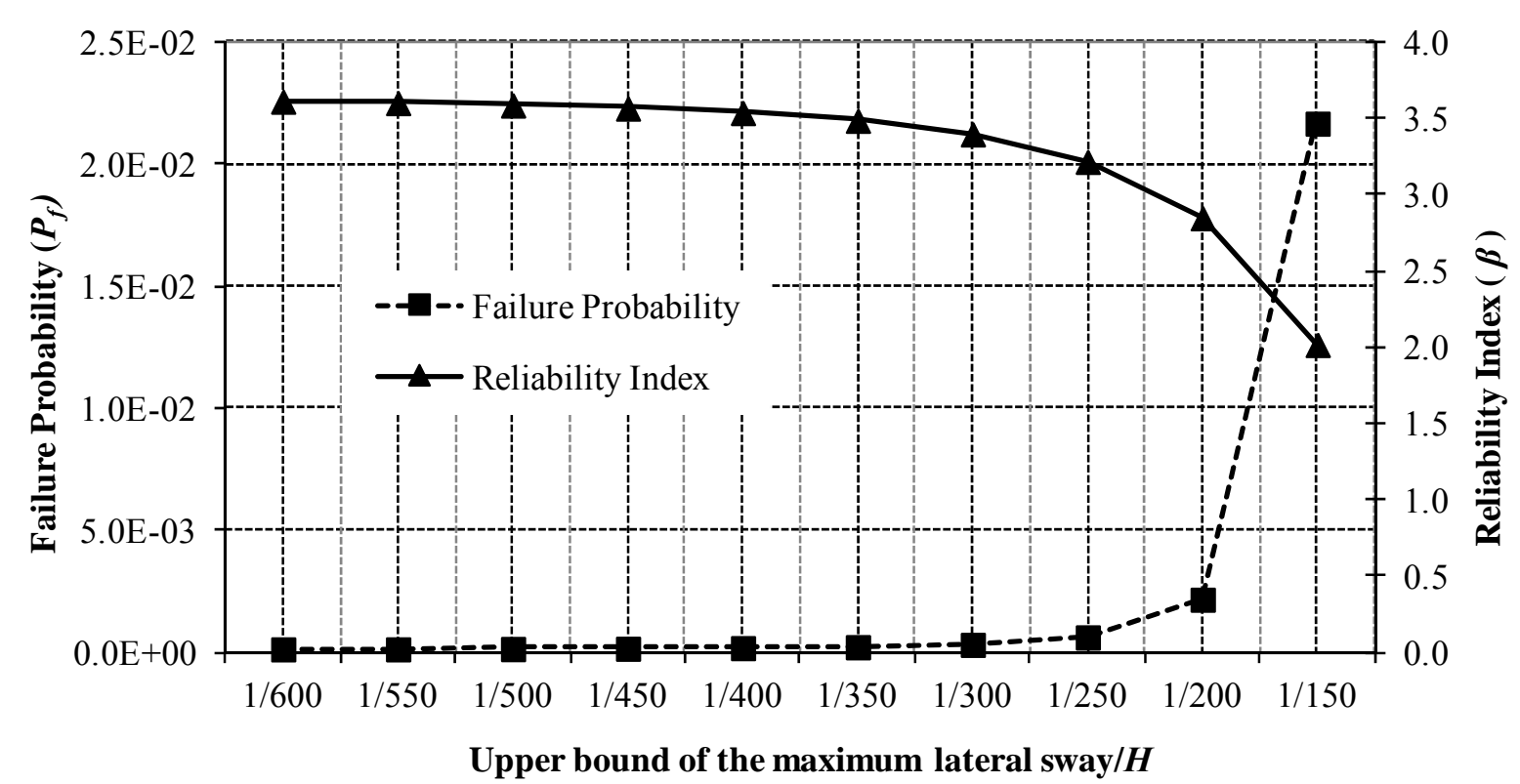

Figure 5. System Reliability Versus the Magnitude of Initial Geometric Imperfection

\section{CONCLUSIONS}

The system reliability of a 3D steel frame with respect to the collapse limit state under the dead and live loads was evaluated using the FORM-based adaptive response surface approach in this study. The structure considered is a typical high-rising office building designed by Ziemian [24] per AISC LRFD [2]. The advanced analysis approach as implemented in SAP2000 that accounts for the $P-\Delta$ and large displacement effect as well as the nonlinear material property was employed to obtain the resistance, i.e. collapse load, of the structure. In the reliability analysis, the uncertainties in the steel yield strength, Young's modulus, cross-sectional area and moment of inertia of the frame members, initial geometric imperfections of the frame, dead load and live load as well as the spatial variability of the live load were taken into account. To achieve a trade-off between computational efficiency and robustness, the resistance of the frame was approximated using the response surface approach based on the collapse loads evaluated from the advanced analysis at sampling points that are adaptively selected during the reliability analysis. The system reliability of the frame was calculated using the FORM based on the adaptively evaluated response surfaces for the resistance.

The system reliability of the frame was evaluated for two cases, namely ignoring and considering 
the spatial variability of the live load. For the former case, the live loads on all the floors in the frame were assumed to be fully correlated. For the latter case, the live loads on the office floors were assumed to be fully correlated; however, the live loads on the office floor, mechanical floor and roof were assumed to be independent of each other. The analysis results indicate that the spatial variability of the live load reduces the system reliability. The impact of such spatial variability on the reliability of the example frame is small due to the fact that the live loads on the majority of the floors were assumed to be fully correlated for Case 2 .

The calculated system reliability of the example 3D steel frame is similar to that of the planar steel frames designed per AISC LRFD [1] and reported in the literature (Hong and Zhou [6]). Sensitivity analyses were carried out to investigate the impact of the variability of the steel yield strength and magnitude of the initial geometric imperfection on the system reliability of the example frame. The analysis results indicate that the system failure probability of the frame increases by almost one order of magnitude if the COV of the yield strength increases from 0.06 to 0.1 . This suggests that quality control of the steel manufacturing process has a large impact on the system reliability of steel frames. The sensitivity analysis results also indicate that the system reliability of the example frame decreases drastically if the upper bound of the uniformly distributed maximum later sway that characterizes the initial geometric imperfection is greater than $H / 250$, which is twice the maximum allowable erection tolerance specified by AISC [2]. Finally, it should be emphasized that the analysis results obtained in this paper are with respect to the particular example considered. However, the methodology for evaluating the system reliability of 3D steel frames presented here can be applied to other types of $3 \mathrm{D}$ steel frame structures, for example, the braced steel frames.

\section{ACKNOWLEDGEMENTS}

The financial support for this research is provided by the Faculty of Engineering at Western University and Natural Sciences and Engineering Research Council of Canada (NSERC) Discovery Grant. Their support is gratefully acknowledged. The constructive comments provided by the anonymous reviewer are gratefully appreciated.

\section{REFERENCES}

[1] American Institute of Steel Construction (AISC), "Load and Resistance Factor Design Specification for Structural Steel Buildings", AISC, Chicago, 1986.

[2] American Institute of Steel Construction (AISC), "Specification for Structural Steel Buildings", AISC, Chicago, 2005.

[3] Canadian Standards Association (CSA), "Design of Steel Structures", CSA S16-09. CSA, Mississauga, Canada, 2009.

[4] Ellingwood, B.R., "Probability-based Codified Design: Past Accomplishments and Future Challenges", Structural Safety, 1994, Vol. 13, No. 3, pp. 159-176.

[5] Ellingwood, B.R., "LRFD: Implementing Structural Reliability in Professional Practice", Engineering Structures, 2000, Vol. 22, No. 2, pp. 106-115.

[6] Zhou, W. and Hong, H.P., "System and Member Reliability of Steel Frames", Steel and Composite Structures, 2004, Vol. 4, No. 6, pp. 419-435.

[7] Li, J. and Li, G., "Reliability-based Integrated Design of Steel Portal Frames with Tapered Members", Structural Safety, 2004, Vol. 26, No. 2, pp. 221-239.

[8] Buonopane, S.G. and Schafer, B.W., "Reliability of Steel Frames Designed with Advanced Analysis”, Journal of Structural Engineering, ASCE, 2006, Vol. 132, No. 2, pp. 267-276. 
[9] Buonopane, S.G., "Strength and Reliability of Steel Frames with Random Properties", Journal of Structural Engineering, ASCE, 2008, Vol. 134, No. 2, pp. 337-344.

[10] Chen, W.F., Goto, Y. and Liew, J.Y.R., "Stability Design of Semi-rigid Frames", John Wiley \& Sons, Inc., New York, 1996.

[11] Huh, J.W., Lee, S.Y. and Haldar, A., "Reliability Evaluation Using Finite Element Method", Proceedings of the $4^{\text {th }}$ International Symposium on Uncertainty Modeling and Analysis, College Park, Maryland, 2003

[12] Hadianfard, M.A. and Razani, R., "Effects of Semi-rigid Behavior of Connections in the Reliability of Steel Frames", Structural Safety, 2003, Vol. 25, No. 2, pp. 123-138.

[13] Zhang, H., Chandrangsu, T. and Rasmussen, K.J.R., "Probabilistic Assessment of the Strength of Steel Scaffold Systems Using Advanced Analysis", Proceedings of the $10^{\text {th }}$ International Conference on Structural Safety and Reliability, Osaka, Japan, 2009.

[14] Zhang, H., Chandrangsu, T. and Rasmussen, K.J.R., "Probabilistic Study of the Strength of Steel Scaffold Systems”, Structural Safety, 2010, Vol. 32, No. 6, pp. 393-401.

[15] Zhang, H., Rasmussen, K.J.R. and Ellingwood, B.R., "Reliability Analysis of Steel Scaffold Shoring Structures", Proceedings of the $11^{\text {th }}$ International Conference on Applications of Statistics and Probability in Civil Engineering, Zurich, Switzerland, 2011.

[16] Computer and Structures Inc. (CSI), "SAP2000 Analysis Reference Manual”, CSI, Berkeley, CA, 2008.

[17] Rackwitz, R. and Fissler, B., "Structural Reliability under Combined Random Load Sequences", Computers \& Structures, 1978, Vol. 9, No. 5, pp. 489-494.

[18] Low, B.K. and Tang, W.H., "Efficient Spreadsheet Algorithm for First-order Reliability Method", Journal of Engineering Mechanics, ASCE, 2007, Vol. 133, No. 12, pp. 1378-1387.

[19] Breitung, K., "Asymptotic Approximation for Multinormal Integrals", Journal of Engineering Mechanics, ASCE, 1984, Vol. 110, No. 3, pp. 357-366.

[20] Der Kiureghian, A., Lin, H.Z. and Hwang, S.J., "Second-order Reliability Approximations", Journal of Engineering Mechanics, ASCE, 1987, Vol. 113, No. 8, pp. 1208-1225.

[21] Huh, J. and Haldar, A., "Seismic Reliability of Non-linear Frames with PR Connections Using Systematic RSM”, Probabilistic Engineering Mechanics, 2002, Vol. 17, No. 2, pp. 177-190.

[22] Zhao, Y.G. and Ono, T., "System Reliability Evaluation of Ductile Frame Structures", Journal of Structural Engineering, 1998, Vol. 124, No. 6, pp. 678-685.

[23] Bucher, C.G. and Bourgund, U., "A Fast and Efficient Response Surface Approach for Structural Reliability Problems”, Structural Safety, 1990, Vol. 7, No. 1, pp. 57-66.

[24] Ziemian, R.D., "Advanced Methods of Inelastic Analysis in the Limit States Design of Steel Structures", PhD dissertation, Cornell Univ., Ithaca, N.Y., 1990.

[25] Ziemian, R.D., McGuire, W. and Deierlein, G.G., "Inelastic Limit States Design. Part II: Three-dimensional Frame Study", Journal of Structural Engineering, 1992, Vol. 118, No. 9, pp. 2550-2568.

[26] Bartlett, F.M., Dexter, R.J., Graeser, M.D., Jelinek, J.J., Schmidt, B.J. and Galambos, T.V., "Updating Standard Shape Material Properties Database for Design and Reliability", Engineering Journal, AISC, 2003, Vol. 40, No. 1, pp. 2-14.

[27] Ellingwood, B.R., Galambos, T.V., MacGregor, J.G. and Cornell, C.A., "Development of Probability Based Load Criterion for American National Standard A58", National Bureau of Standard Special Publication 577, Faithersburg, Md, 1980. 